\title{
Erratum to: Axial Imidazole Binding Strengths in Porphyrinoid Cobalt(III) Complexes as Studied by Tandem Mass Spectrometry
}

\author{
Ekta Mishra, ${ }^{1}$ Jill L. Worlinsky, ${ }^{2}$ Thomas M. Gilbert, ${ }^{1}$ Christian Brückner, ${ }^{2}$ Victor Ryzhov ${ }^{1}$ \\ ${ }^{1}$ Department of Chemistry and Biochemistry, Northern Illinois University, DeKalb, IL 60115, USA \\ ${ }^{2}$ Department of Chemistry, University of Connecticut, Storrs, CT 06269, USA
}

\begin{abstract}
The Co(II) complexes of twelve meso-tetraaryl-porphyrins, -chlorins, and chlorin analogues containing non-pyrrolic heterocycles were synthesized and converted in situ to the corresponding $\mathrm{Co}$ (III) complexes coordinated to one or two imidazoles. Electrospray ionization tandem mass spectrometry (ESI-MS/MS) in conjunction with the energy-variable collision-induced dissociation (CID) technique was used to compare the relative gas-phase binding strength of the axially coordinated imidazoles to the octahedral and square planar $\mathrm{Co}$ (III) porphyrinoid complex ions. The observed binding energies of these ligands were rationalized in terms of the effects of porphyrinoid core structure and meso-substitution on the electron density on the central $\mathrm{Co}$ (III) centers. Some of these trends were supported by DFT-based computational studies. The study highlights to which extend porphyrins vary from chlorins and chlorin analogues in their coordination abilities and to which extraordinary degree meso-thienyl-substituents influence the electronic structure of porphyrins. The study also defines further the scope and limits CID experiments can be used to interrogate the electronic structures of metalloporphyrin complexes.
\end{abstract}

Key words: Porphyrins, Porphyrin analogues, Tandem mass spectrometry, Metalloporphyrinligand interactions, DFT calculations

\section{Introduction}

$\mathrm{P}$ orphyrins and chlorins (2,3-dihydroporphyrins) play a crucial role in many biological and chemical processes $[1,2]$. Generally in the form of their metal complexes, they function, for example, as prosthetic groups in oxidation catalysts

The online version of the original article can be found at http://dx.doi.org/ 10.1007/s13361-011-0330-6

Due a production error, there were numerous formatting and typesetting errors in the original version of this article. Thus, we have reproduced the article in its entirety.

Electronic supplementary material The online version of this article (doi:10.1007/s13361-012-0412-0) contains supplementary material, which is available to authorized users.

Correspondence to: Christian Brückner; e-mail: c.bruckner@uconn.edu, Victor Ryzhov; e-mail: ryzhov@niu.edu
[2], reversible oxygen transporters [3], catalysts in hydrocarbon biosynthesis [4], are believed to be involved in the cellular delivery of oligonucleotides [5] and oligoribonucleotides [6], or they function as antennas and reactive centers in light harvesting systems [7].

Mimicking their natural counterparts, synthetic porphyrins have enormous potential to be used as catalysts, light harvesting chromophores, sensors, or photo-activated drugs $[2,8]$. meso-Tetraarylporphyrin-derived systems are the most popular synthetic porphyrin class because of their facile synthesis and derivatization [9, 10]. Cobalt(II)/(III) complexes of meso-tetraarylporphyrins have been utilized as oxidation catalysts $[1,11]$, small molecule activation and transfer catalysts [12], and as electro-catalyst in, for instance, the four-electron reduction of dioxygen $[13,14]$.

Most reactions of naturally occurring and synthetic metalloporphyrins involve noncovalent interactions between the 
metalloporphyrins and various axial ligands $[15,16]$. The presence of one or two axial ligands (L) expands the square planar $\mathrm{N}_{4}$-donor set of the dianionic porphyrin ligand to form square pyramidal $\mathrm{N}_{4} \mathrm{~L}$ or octahedral $\mathrm{N}_{4} \mathrm{~L}_{2}$ coordination spheres around the central metal, respectively (Figure 1) [17]. In nature, the axial ligands are frequently imidazoles from His protein side chains [15]. The strength of this interaction is governed by the intrinsic strength of the $\sigma$-donor interaction of the nitrogen lone pair on the imidazole with the central metal. In proteins, the imidazole is generally held in place by the protein, thereby greatly increasing its binding strength.

Multiple studies have been performed to probe the interaction of metalloporphyrins with a variety of ligands and the binding constants derived were tabulated $[18,19]$. However, due to the limited water-solubility of many metalloporphyrins, it is difficult to study the macrocycle structure-dependence of these processes in aqueous media. To separate out solvent effects altogether, metal-ligand complexes have become the subject of gas-phase thermochemical studies. Particularly electrospray ionization mass spectrometry (ESI-MS) plays an ever-increasing role in the analysis and characterization of noncovalent complexes [20]. This technique has been applied to the study of metalloporphyrin axial ligand interactions. For instance, the loss of heme from hemoglobin [21] and myoglobin was probed by collision-induced dissociation (CID) [22] and blackbody infrared dissociation [23]. Also, infrared multiphoton dissociation [24], radiative association, equilibrium and the kinetic methods have been used to estimate the binding strength of various axial complexes of metalloporphyrins [25].

Relative binding energies of noncovalent interactions can also be probed using conventional CID [26]. Many commercial mass spectrometers with tandem MS capabilities, including quadrupole ion traps, are suitable for CID experiments. Energy-variable CID experiments using quadrupole ion traps to estimate the energetics of noncovalent binding parameters were popularized by the groups of Hart and McLuckey [27], and Colorado and Brodbelt [28]. This technique probes the kinetic stability of ions leading to thermodynamic estimates. While it is mostly used for the relative comparisons between similar complexes, a correlation between the energy-variable CID results and absolute dissociation energy was established, allowing the comparison of dissimilar systems [29-32].

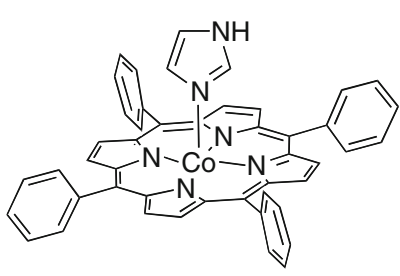

$\mathrm{N}_{4} \mathrm{~L}$ - square pyramidal [1(Imi)]Co

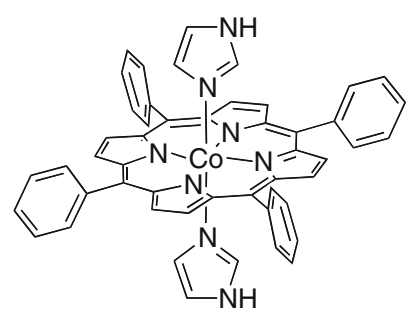

$\mathrm{N}_{4} \mathrm{~L}_{2}$ - octahedral [1(Imi) $\left.)_{2}\right] \mathrm{Co}$
Figure 1. Structures of [1(Imi)]Co and [1(Imi) $\left.)_{2}\right]$ Co as representative for the two principle types of imidazole-metalloporphyrin complexes investigated
We published several studies that use energy-variable CID to obtain the relative binding order of various ligands to metalloporphyrins. The ligands probed included His-containing peptides [29], other peptides [30], nitrogen bases [31], and malaria drugs and their model compounds [32]. Those studies involved varying the ligands in complexes of a single metalloporphyrin, such as the Fe(III), Mn(III), and Co(III) complexes of meso-tetraphenylporphyrin 1 [32]. Thus, near-identical metal ion-nitrogen bonds were considered but the vibrational degrees of freedom (DOF) of the ligand varied with the length of the peptide. We showed that in these types of systems the $E_{1 / 2}$ values and the number of vibrational DOF of the complex were linearly correlated, a finding that was rationalized in terms of RRK theory [31].

We study here the effect of the porphyrin macrocycle structure on the axial ligand binding of their cobalt complexes, whereby we vary systematically only the structure of the porphyrinoid macrocycle, including a variation of the mesosubstituents. We take advantage of a number of recently reported porphyrin analogues in which a pyrrolic building block of a porphyrin was replaced by a non-pyrrolic heterocycle. This is the first study that compares the coordination properties of a range of pyrrole-modified porphyrins. As in previous work [30, 32], we chose Co(III) as the central metal and imidazole as the axial ligand. While the electronic structure of porphyrin cobalt complexes, the influence of halogen substitution on the porphyrins, and the influence of axial ligands has been thoroughly studied using experimental and computational methods [33,34], we are not aware of comparable investigations that studied the electronic structures of chlorin cobalt complexes.

The porphyrins selected are the benchmark porphyrin [mesotetraphenylporphyrinato]Co [1]Co and its more electron-rich 3,4,5-trimethoxy derivative [9]Co (Figure 1). The optical properties of [1]Co and [9]Co are only very little different, highlighting the small interaction between the two essentially perpendicular $\pi$-systems on the meso-aryl rings and the porphyrinoid chromophore (all UV-vis spectra are provided as electronic supplementary material). The smaller meso-2-thienyl substituents (in [10]Co and [11]Co) can assume a much more co-planar conformation, enabling a much stronger interaction with the porphyrinic chromophore, while the sterically more demanding 3-thienyl substituent takes up an intermediate position between [10]Co and [1]Co [35, 36]. Presumably the trend seen in the optical properties will also be reflected in the coordination properties of the central metal, a hypothesis as yet untested (Figure 2).

Metallochlorins [4]Co and [8]Co are the 2,3-dihydroxychlorin analogues to porphyrins $[1] \mathrm{Co}$ and $[9] \mathrm{Co}$, respectively [37]. Owing to their nature as reduced porphyrins, they possess higher HOMO levels compared to porphyrins [38]. Thus, they may be considered more electron-rich (better $\mathrm{e}^{-}$-donors) than porphyrins. However, the parent meso-tetraphenylchlorin (meso-tetraphenyldihydroporphyrin) is reportedly less Brønsted-basic than the corresponding porphyrin [39], and the pyrrolidine-M bonds in metallochlorin complexes are generally longer than the 

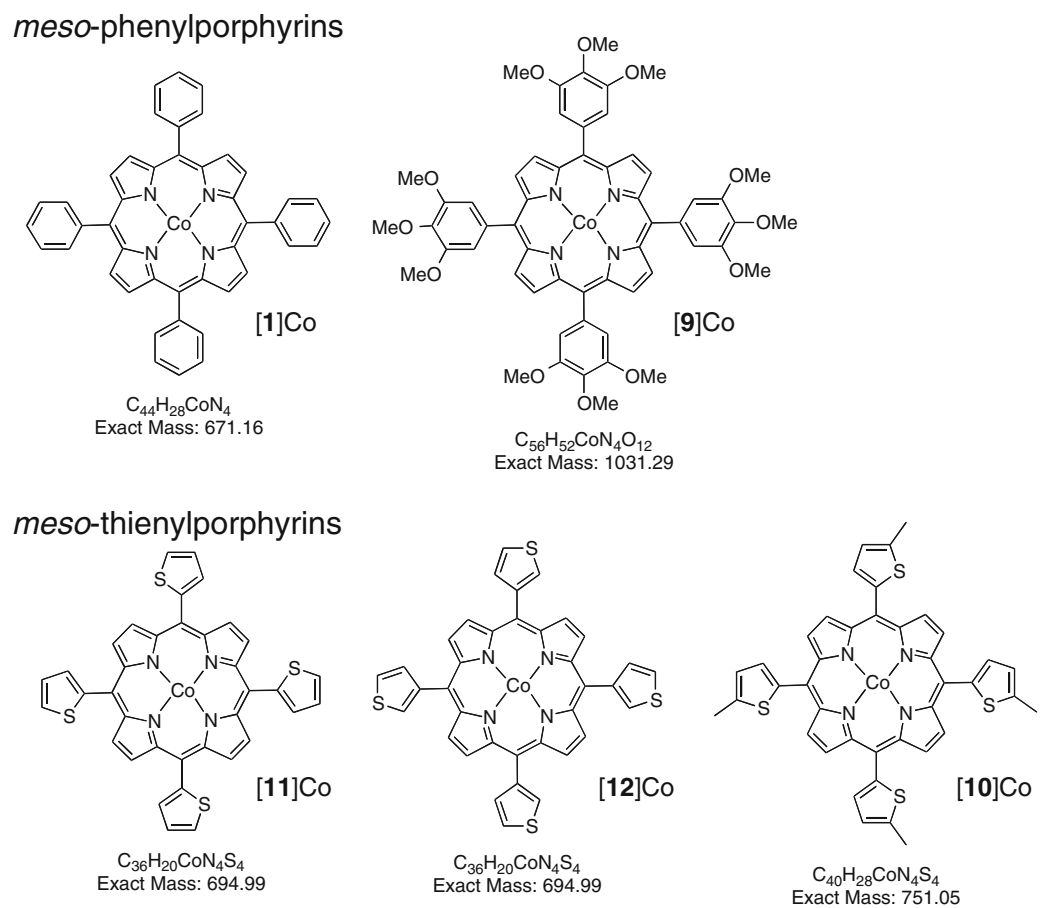

meso-phenylchlorins
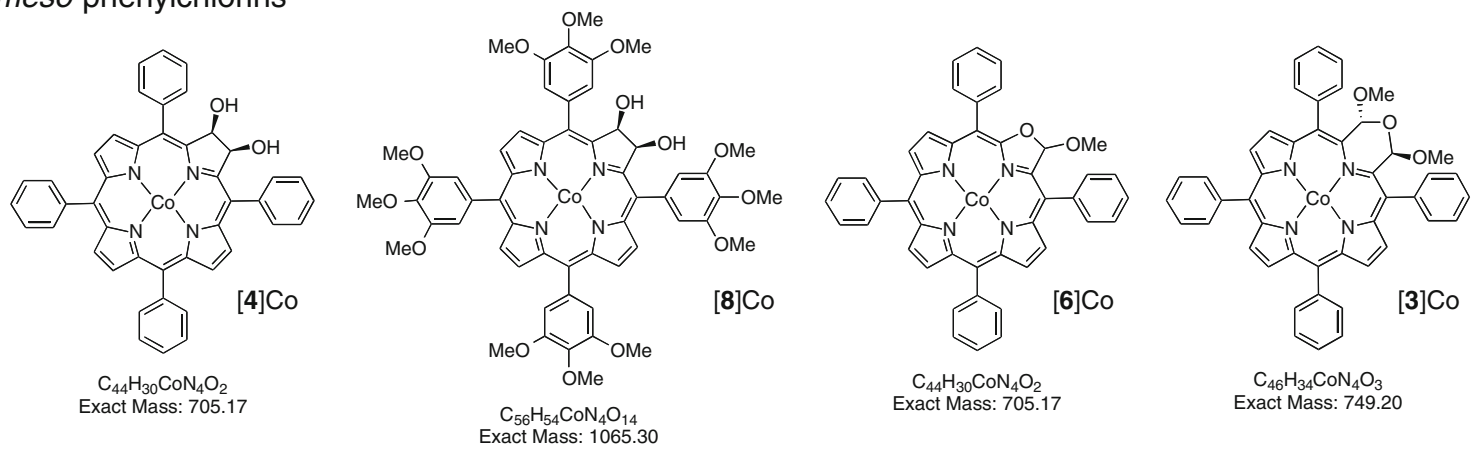

meso-phenyl-oxo-porphyrins
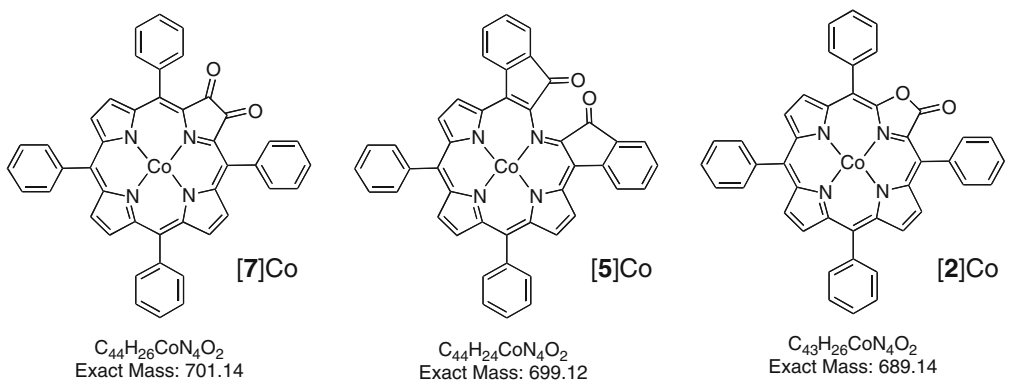

Figure 2. Structures of 12 cobalt(II) porphyrinoid complexes investigated

corresponding pyrrole-M bonds in porphyrins, suggesting that they are worse $\sigma$-donors. The UV-Vis spectra of $\mathbf{4}$ and [4]Co are, as a result of the hydroxy substitution at the benzylic positions [40], not bathochromically shifted compared with those of porphyrins 1 and [1]Co, respectively, indicating that all three chromophores have very similar HOMO-LUMO gaps. The inclusion of chlorins into this study will reveal to which extent their electronic structure will influence the binding of imidazole to their $\mathrm{Co}(\mathrm{III})$ complexes. A comparison of tetraphenyl-substituted tetra (3,4,5-trimethoxy)phenyl-substituted complex [4]Co and [8]Co will mirror the influence of the meso-aryl group that is observed between [1]Co and [9]Co, if any exists.

2,3-Dioxoporphyrin complex [7]Co is the oxidized version of chlorin [4]Co and porphyrin [1]Co [41]. As such, it is expected to be significantly less electron-rich. Porpho- 
lactone [2]Co is technically also an oxidized porphyrin [42, 53]. The formal replacement of the pyrrole moiety in a porphyrin by an oxazolone moiety was shown to be barely reflected in the UV-Vis spectrum of the free base compound but to result in a metallochlorin-type spectrum of the metal complexes [42]. This is also the case for the [2] Co complex studied here. Its inclusion into the ligand binding study will reveal if it behaves more like a metalloporphyrin ([1]Co), a metallochlorin $([4] \mathrm{Co})$, or a metallodioxoporphyrin ([7]Co).

Reduction of porpholactone [2]Co generates a chlorin-like chromophore, a so called oxazolochlorin [6]Co (here in the form of its more tractable and stable methyl acetal) [47]. As judged by its optical properties, its coordination properties are expected to be much more similar to those of diolchlorin complex [4]Co than those of porpholactone [2]Co. We have also included two pyrrole-modified porphyrins, morpholinochlorin [3] Co, and indaphyrin [5] Co in our study [43, 44, 45]. While free base morpholinochlorin 3 incorporating a sixmembered ring in the macrocycle structure is nearly as planar as a porphyrin/chlorin and it possesses chlorin-like optical properties [43], its coordination properties may be significantly different than those of porphyrins or chlorins. This is because this morpholinochlorin possesses a much increased conformational flexibility than the parent porphyrin or chlorin [46]. Indaphyrin [5]Co is a severely non-planar porphyrinoid with an optical spectrum unlike that of any other porphyrin or chlorin $[44,45]$. Nonetheless, there are structural similarities to dioxoporphyrin [7]Co as both contain carbonyl groups at the (former) pyrrole $\beta$-positions.

\section{Experimental}

\section{Porphyrin Syntheses}

The Co(II) complexes [1]Co through [12]Co were synthesized using classic metal ion insertions into the corresponding known free bases that were all prepared along literature procedures: The free base porphyrins $\mathbf{1}$ and $\mathbf{9}$ were made according to the method of Adler [9], as were the free base thienylporphyrins $\mathbf{1 0}$ through 12 [36]. Free base diolchlorins 4 and 8 were prepared by $\mathrm{OsO}_{4}$-mediated dihydroxylation of the corresponding porphyrins [37, 40]. Free bases of porpholactones 2 [43], dioxoporphyrin 7 [42], indaphyrin 5 [45], and morpholinochlorin 3 [43] were made by oxidation/derivatization of free base meso-tetraphenyl-2,3-diolchlorin 4 . Free base oxazolochlorin 6 was obtained by reduction and acetalization of the corresponding porpholactone [48]. Details to the synthesis of the Co(II) complexes and their UV-Vis spectra are provided in the Supplementary Materials Section.

\section{Mass Spectrometry}

Imidazole and all solvents were obtained from Aldrich (Milwaukee, WI, USA) and used without further purification. For the binding energy studies, the imidazole complexes of the Co(II) porphyrinoids $\mathbf{1}$ through $\mathbf{1 2}$ were generated in the solution phase by mixing $0.1 \mathrm{M}$ solutions of porphyrins and imidazole in acetonitrile. The solutions were diluted to $\sim 10^{-4} \mathrm{M}$ with acetonitrile for the infusion into the mass spectrometer.

Experiments were performed on a Thermo Finnigan-LCQ Advantage (ThermoFisher, San Jose, CA, USA) quadrupole ion trap mass spectrometer equipped with an ESI source. The mass spectrometer was operated in the positive ion mode. For the binding energy studies, the porphyrinimidazole complexes were infused by syringe pump at a flow rate of $5 \mu \mathrm{L} / \mathrm{min}$. The ESI source conditions were as follows: capillary temperature, $200{ }^{\circ} \mathrm{C}$; spray voltage, $4.5 \mathrm{kV}$; nebulizer gas, 30-35 arbitrary units. Capillary exit and skimmer voltages were optimized to maximize the yield of the ions of interest. The singly charged cobalt(III) porphyrin cationic complexes with one or two imidazoles ([(Por)(Imi) $] \mathrm{Co}^{\mathrm{III}} 7^{+}$and $\left[(\right.$Por $\left.)(\mathrm{Imi})_{2}\right] \mathrm{Co}^{\mathrm{III}} 7^{+}$) were formed by (electrochemical) oxidation of the neutral cobalt(II) porphyrinoid complexes during the electrospray process. These ions were isolated in the ion trap and subjected to CID (isolation width $2-4 \mathrm{~m} / \mathrm{z}, \mathrm{q}_{\mathrm{z}}=0.25$, activation time $30 \mathrm{~ms}$ ). Energy-variable CID experiments were performed by ramping the resonance excitation voltages from $0 \mathrm{~V}$ to the value corresponding to the total dissociation of the complex. Plots of the relative abundance of the parent ion versus applied normalized collisional energy were generated to determine $E_{1 / 2}$ values [48]. $E_{1 / 2}$ voltages were taken at resonance excitation voltage values at which the intensity of the porphyrin-imidazole complex and porphyrin ions were equal. These dissociation curves were obtained in triplicate for each complex. The normalized collision energy (NCE\%) was then converted to the amplitude in volts using Equation (1) which was obtained from the instrument manufacturer (Thermo).

Amplitude $(\mathrm{V})=\mathrm{NCE} \% / 30 \%$

\{parent mass*tick amp slope + tick amp intercept $\}$

Where tick amp is the amplitude of the resonance excitation RF voltage (amplitude of the "tickle voltage"). The value for tick amp slope is $0.989 \mathrm{mV} / \mathrm{u}$ and tick amp intercept is $0.428374 \mathrm{~V}$. The $\mathrm{E}_{1 / 2}$ values obtained were corrected for the number of degrees of vibrational freedom (DOF) (3 N-6), according to Equation (2) [48].

$$
\mathrm{E}_{1 / 2}{ }^{\prime}=\mathrm{E}_{1 / 2} / \mathrm{DOF}
$$

\section{Computational Methods}

All calculations were performed with the GAUSSIAN (G09) code [49]. Porphyrins and cobalt(III) porphyrin complexes were fully optimized without constraints at the DFT M06L level [50] using the mixed basis set BSA2. This treated Co atoms using the spin-state corrected s6-31 G* 
basis set of Swart et al. [51] that is based on previously reported 6-31 $\mathrm{G}^{*}$ basis sets $[52,53], \mathrm{N}$ atoms using the 6-31 $+\mathrm{G}(\mathrm{d})$ basis set, and all other atoms using the 6-31 G basis set [54]. The M06L model was chosen because prior work showed it to be a superior DFT model for studies of energetics of transition metal complexes [50]. The spin ground state for each complex was determined by testing the wave function with the keyword "Stable", and/or by optimizing the complex using different choices for the multiplicity. All the $\left[(\mathrm{Por})(\mathrm{Imi})_{2}\right] \mathrm{Co}^{\mathrm{III}} 7^{+}$complexes proved to be singlets, all the $[(\mathrm{Por})(\mathrm{Imi})] \mathrm{Co}^{\mathrm{III}} 7^{+}$complexes proved to be triplets save $[(\mathbf{4})(\mathrm{Imi})] \mathrm{Co}^{\mathrm{III}} 7^{+}$and $[(\mathbf{1 3})(\mathrm{Imi})] \mathrm{Co}^{\mathrm{III}} 7^{+}$, both singlets, and all [(Por) $] \mathrm{Co}^{\mathrm{III}} 7^{+}$complexes proved to be triplets (Figure 3).

Examination of the optimized structures by analytical frequency analysis at the M06L/BSA2 level demonstrated them to be minima (no imaginary frequencies). Natural Bond Order (NBO) [55] and Hirshfeld charge [56] calculations were performed using subroutines in the Gaussian program, using the M06L/BSA2-optimized structures and wave functions.

To assess the effect of a DFT model modified to take into account some degree of dispersion, some molecules were reoptimized using the wB97XD/BSA2 approach [57]. This model gave energies modestly different from those determined using the M06L model, but did not give different trends.

As a perturbation theory check on the DFT-determined energetics, single point energies were determined on some complexes using the M06L/BSA2-optimized structures and a two-layered ONIOM [58, 59] approach employing the $\operatorname{CCSD}(\mathrm{T}) / 6-311+\mathrm{G}(2 \mathrm{df}, 2 \mathrm{p})$ model for the high layer and the M06L/6-31+G(d) model for the low layer. In the usual shorthand, the model chemistry was ONIOM(CCSD(T)/6-311+G(2df,2p):M06L/6-31+G (d)//M06L/BSA2. The layering scheme appears in the Supporting Information. This approach also provided M06L/6-31+G(d)//M06L/BSA2 energies that could be compared with the M06L/BSA2 energies to assess the effect of basis set size.

For all model chemistries employed, relative energies were corrected using unscaled zero point energies (ZPEs) from the frequency analysis. Data appear in Table 2.

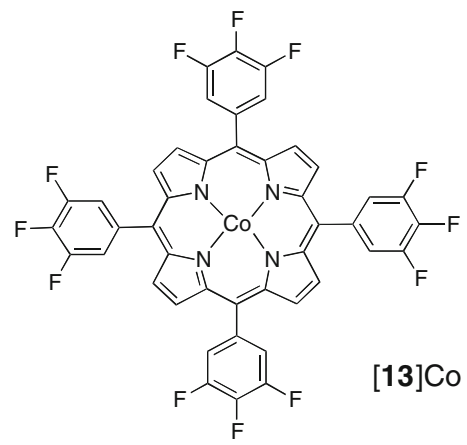

Figure 3. Structure of the computed cobalt(II) porphyrin [13]Co

\section{Results and Discussion}

\section{Complex Ion Formation and Analysis}

Singly charged [porphyrinato]Co(III)-imidazole complexes $\left[(\right.$ Por)(Imi) $] \mathrm{Co}^{\mathrm{III}} 7^{+}$and $\left[(\right.$Por $\left.)(\operatorname{Imi})_{2}\right] \mathrm{Co}^{\mathrm{IIII}} 7^{+}$were formed by injection of a mixture of acetonitrile solutions of imidazole and the porphyrinoid $\mathrm{Co}$ (II) complexes [1]Co through [12]Co into the ESI source. Ionization was brought about by a single electron oxidation in the source, a commonly observed phenomenon for $\mathrm{Ni}(\mathrm{II}), \mathrm{Ag}(\mathrm{II}), \mathrm{Mn}(\mathrm{II}), \mathrm{Fe}(\mathrm{II})$, or $\mathrm{Co}(\mathrm{II})$ porphyrins upon analysis by ESI-MS in the positive ion mode [30, 47].

All compounds under study formed complexes with one and two molecules of imidazole ([(Por)(Imi) $] \mathrm{Co}^{\mathrm{III}} 7^{+}$and $\left[(\right.$ Por $\left.)(\mathrm{Imi})_{2}\right] \mathrm{Co}^{\mathrm{III}} 7^{+}$, respectively). In CID experiments of both types of complex ions, the lowest energy dissociation process observed involved the loss of a single imidazole, resulting in the formation of the square pyramidal complex $[(\mathrm{Por})(\mathrm{Imi})] \mathrm{Co}^{\mathrm{III}} 7^{+}$in the case of dissociation of the octahedral complex $\left[(\mathrm{Por})(\mathrm{Imi})_{2}\right] \mathrm{Co}^{\mathrm{III}} 7^{+}$(Equation 3), and the formation of the square planar complex [(Por)(Imi) $] \mathrm{Co}^{\mathrm{IIII}} 7^{+}$when the dissociation of $[($ Por $)(\mathrm{Imi})] \mathrm{Co}^{\mathrm{III}} 7^{+}$is considered (Equation 4).

$$
\begin{gathered}
{\left[(\text { Por })(\operatorname{Imi})_{2}\right] \mathrm{Co}^{\mathrm{III}\rceil^{+}} \rightarrow[(\text { Por })(\operatorname{Imi})] \mathrm{Co}^{\mathrm{III}\rceil^{+}}+\text {Imi }} \\
{[(\text { Por })(\text { Imi })] \mathrm{Co}^{\mathrm{III}\rceil^{+}} \rightarrow[(\text { Por })] \mathrm{Co}^{\mathrm{III}\rceil^{+}}+\text {Imi }}
\end{gathered}
$$

The relative dissociation energies of the noncovalent complexes were obtained by energy-variable CID. Representative CID spectra for the dissociation of the [(1)(Imi)] $\mathrm{Co}^{\mathrm{III}} 7^{+}$and $\left[(\mathbf{1})(\mathrm{Imi})_{2}\right] \mathrm{Co}^{\mathrm{III}} 7^{+}$are shown in Figure 4, and a typical energy-variable CID curve (for the dissociation of the $\left.[(\mathbf{1})(\mathrm{Imi})] \mathrm{Co}^{\mathrm{III}} 7^{+}\right)$is shown in Figure 5. From these curves, the relative $\mathrm{E}_{1 / 2}$ values for all mono- and bis-imidazole complexes were extracted (Tables 1 and 2).

Brodbelt and co-workers showed that relative metal-ligand binding in systems of similar chemical character can be quickly screened by normalizing the $E_{1 / 2}$ values of the complexes with respect to the number of DOF of all ligands coordinated to the central metal [48], here the DOF of the porphyrinoid and the axial imidazoles. The systems in this study are quite comparable: they all possess identical axial ligand(s) and central metal and all are coordinated to a similar square planar dianionic porphyrinoid $\mathrm{N}_{4}$ donor set. Thus, their similarity makes them excellent candidates for this approach. The resulting $\mathrm{E}_{1 / 2}$ ' values representing the binding strength per DOF. The $\mathrm{E}_{1 / 2}$ ' values allow a comparison of the relative binding energies. The higher the binding energy for a given dissociation process, the stronger the complex.

\section{Relative Binding Strength of a Single Axial Imidazole in the Octahedral Complexes [(Por) (Imi) 2$\left.] \mathrm{Co}^{\mathrm{III}}\right\rceil^{+}$}

The $\mathrm{E}_{1 / 2}$ ' values for the CID of bis-imidazole complexes of type $\left[(\right.$ Por $\left.)(\mathrm{Imi})_{2}\right] \mathrm{CO}^{\mathrm{III}} 7^{+}$losing a single imidazole (accord- 
(a)

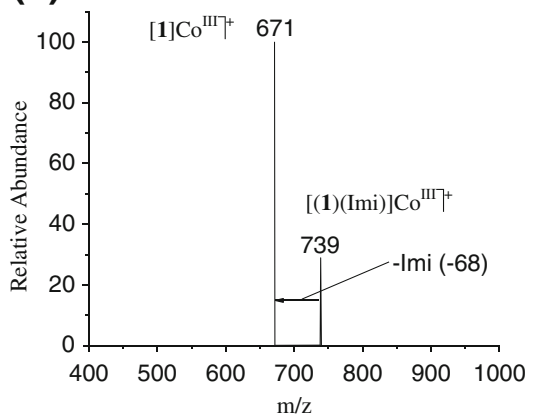

(b)

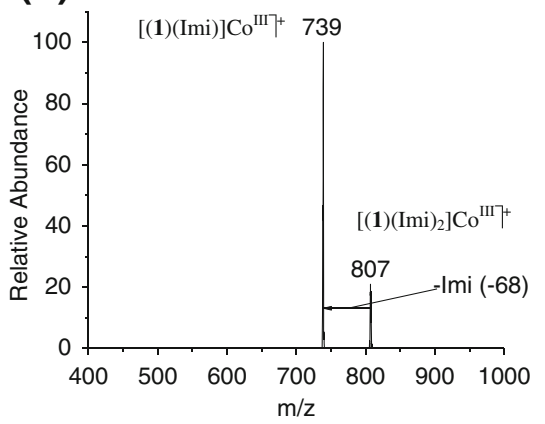

Figure 4. CID spectrum of complex [1] Co ${ }^{+}$bound to imidazole. (a) CID of complex [(1)(Imi)]Co ${ }^{111} 7^{+}$showing the loss of a single imidazole forming [1] $\mathrm{Co}^{\mathrm{III}} 7^{+}$(cf. to Equation 4). (b) $\mathrm{CID}$ of $\left[(\mathbf{1})(\mathrm{Imi})_{2}\right] \mathrm{Co}^{\mathrm{III} 7^{+}}$complex showing the loss of a single axial imidazole forming $\left[(\mathbf{1})(\right.$ Imi) $] \mathrm{Co}^{\mathrm{III}} 7^{+}$(cf. to Equation 3)

ing to Equation 3) vary between the $\mathbf{1 2}$ porphyrinoids investigated, with values ranging from $1.88 \mathrm{mV}$ for the loss of a single imidazole from the chlorin complex $\left[(\mathbf{8})(\operatorname{Imi})_{2}\right]$ $\mathrm{Co}^{\mathrm{III}} 7^{+}$to $3.12 \mathrm{mV}$ for the corresponding process in the meso-thienylporphyrin complex $\left[(\mathbf{1 1})(\mathrm{Imi})_{2}\right] \mathrm{Co}^{\mathrm{III}} 7^{+}$(Table 1, column D). But rather than analyzing this data in absolute terms, it might be more illustrative to compare the data trends expressed in terms of \%change relative to the corresponding process in the benchmark tetraphenylporphyrin system $\left.\left[(\mathbf{1})(\mathrm{Imi})_{2}\right] \mathrm{Co}^{\mathrm{III}}\right\rceil^{+}\left(\mathrm{E}_{1 / 2}{ }^{\prime}\right.$ value of $\left.2.55 \mathrm{mV}\right)$. The relative change is listed in Table 1, column E.

The data show some expected and some surprising trends, not all of which will find simple explanations. For instance, making the complex more electron-rich by means of decorating the meso-aryl groups with a total of 12 methoxy groups as in $\left[(9)(\operatorname{Imi})_{2}\right] \mathrm{Co}^{\mathrm{III}} 7^{+}$, increases the electron density of the porphyrin donor set. In turn, this makes the cobalt center more electronrich and, consequently, this reduction in Lewis acidity weakens the bond to the axial imidazole by $11 \%$. in part unexpected, the $\mathrm{E}_{1 / 2}{ }^{\prime}$ values measured for most chlorin complexes are only $1 \%-$ $5 \%$ elevated compared with the corresponding value of the benchmark porphyrin complex, except when the chlorin is combined with the electron-rich trimethoxyphenyl group. Thus, in complex $\left[(\mathbf{8})(\mathrm{Imi})_{2}\right] \mathrm{Co}^{\mathrm{III}} 7^{+}$the $\mathrm{E}_{1 / 2}$ ' value is reduced by $26 \%$, to $1.88 \mathrm{mV}$. On the other hand, the electron-poor, oxidized porphyrinoids porpholactone $\mathbf{2}$, indaphyrin $\mathbf{5}$, and dione $\mathbf{7}$, all

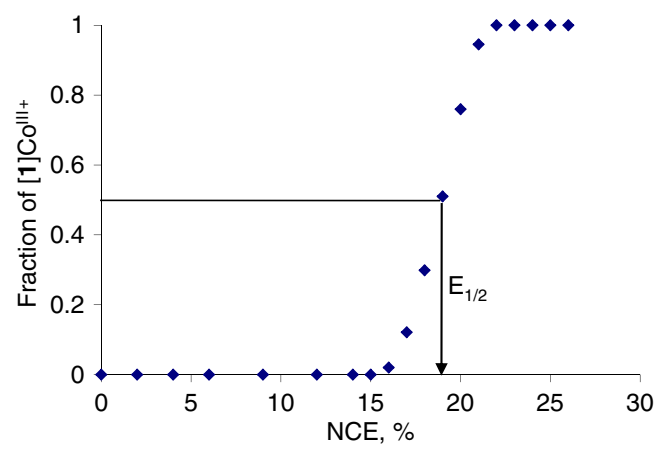

Figure 5. Energy-variable CID curve for $[(\mathbf{1})(\operatorname{Imi})] \mathrm{Co}^{111} 7^{+}$ show $8 \%$ to $17 \%$ increased $\mathrm{E}_{1 / 2}$ ' values, as could be expected based on the increased Lewis acidity of the central metal when coordinated to an electron-poor ligand.

The three thienylporphyrin complexes [(10)(Imi) $\left.)_{2}\right]$ $\mathrm{Co}^{\mathrm{III}} 7^{+}$through $\left[(\mathbf{1 2})(\mathrm{Imi})_{2}\right] \mathrm{Co}^{\mathrm{III}} 7^{+}$show higher $\mathrm{E}_{1 / 2}{ }^{\prime}$ values than measured for a regular or even oxidized porphyrins $(19 \%, 22 \%$, and $14 \%$ higher than the benchmark porphyrin). This is surprising as the redshifted optical spectra of the thienylporphyrins and their cobalt complexes suggested the presence of an electronrich ligand. This is even though a red-shifted optical spectrum does only indicate a reduced HOMO-LUMO gap. In porphyrins, however, this is frequently achieved by the raising of the HOMO level by introducing electron-donating substituents to the chromophore.

The electronic structure of the octahedral $\mathrm{d}^{6}$ complexes are similar in that all are singlet state compounds (see also the computations below). Steric effects potentially also play a role in the modulation of the ligand binding strength but the immediate binding hemispheres around the central metals are believed to be very comparable across all complexes as none of the porphyrinoids investigated possess ortho-substituents on the meso-aryl groups. Before we interpret the finding any further, it is helpful to consider the trends measured for the $E_{1 / 2}$ ' values for the loss of the second imidazole from the square pyramidal complexes.

\section{Relative Binding Strength of the Axial Imidazole in the Square Pyramidal Complexes[(Por)(Imi)] $\mathrm{Co}^{\mathrm{III}} 7^{+}$}

The $\mathrm{E}_{1 / 2}$ ' values for the CID of mono-imidazole complexes of type $[($ Por $)(\mathrm{Imi})] \mathrm{Co}^{\mathrm{III}} 7^{+}$losing the lone imidazole to form the square planar complex $[($ Por $)] \mathrm{Co}^{\mathrm{III}} 7^{+}$(Equation 4) vary substantially between the $\mathbf{1 2}$ porphyrinoids investigated, with values range from 1.50 to $3.50 \mathrm{mV}$ (Table 2, column D). This reflects the sum of the electronic effects of the various meso-substituents and porphyrinoid cores on the central $\mathrm{Co}(\mathrm{III})$ atom. Again, the $\mathrm{E}_{1 / 2}$ ' values are best compared against that measured for the benchmark metal- 
Table 1. Relative Imidazole Binding Energies Recorded for the Dissociation of the Imidazole from [(Por)(Imi) $\left.)_{2}\right] \mathrm{Co}^{\mathrm{III}_{5}+}$ (Equation 3$)$

\begin{tabular}{|c|c|c|c|c|c|c|}
\hline \multicolumn{2}{|l|}{ Processes } & A & B & $\mathrm{C}$ & $\mathrm{D}$ & E \\
\hline$\left[(\right.$ Por $\left.)(\operatorname{Imi})_{2}\right] \mathrm{Co}^{\mathrm{III}} 7^{+} \rightarrow[($ & $7^{+}+$Imi (Equation 3) & $\mathrm{E}_{1 / 2}(\% \mathrm{NCE})$ & $\mathrm{E}_{1 / 2}(\mathrm{~V})$ & DOF (3 N-6) & $\mathrm{E}_{1 / 2}(\mathrm{mV})$ & $\begin{array}{l}\% \Delta \text { of } E_{1 / 2}{ }^{\prime}[\text { Por }] \text { Co relative } \\
\text { to } E_{1 / 2}{ }^{\prime}[1] \mathrm{Co}\end{array}$ \\
\hline \multirow[t]{2}{*}{ Porphyrins } & {$[1] \mathrm{Co}$} & 17.4 & 0.711 & 279 & 2.55 & - \\
\hline & [9]Co & 18.3 & 0.966 & 423 & 2.28 & -11 \\
\hline Porpholactone & {$[2] \mathrm{Co}$} & 19.5 & 0.809 & 276 & 2.93 & 15 \\
\hline \multirow{4}{*}{ Chlorins } & [4] Co & 18.5 & 0.777 & 291 & 2.67 & 5 \\
\hline & {$[8] \mathrm{Co}$} & 15.2 & 0.819 & 435 & 1.88 & -26 \\
\hline & {$[3] \mathrm{Co}$} & 19.5 & 0.804 & 312 & 2.58 & 1 \\
\hline & [6]Co & 18.3 & 0.769 & 291 & 2.64 & 4 \\
\hline \multirow[t]{2}{*}{ Oxoporphyrins } & {$[5] \mathrm{Co}$} & 19.5 & 0.815 & 273 & 2.99 & 17 \\
\hline & [7]Co & 18.3 & 0.766 & 279 & 2.75 & 8 \\
\hline \multirow[t]{3}{*}{ meso-Thienylporphyrins } & {$[10] \mathrm{Co}$} & 19.4 & 0.844 & 279 & 3.03 & 19 \\
\hline & {$[11] \mathrm{Co}$} & 18.2 & 0.759 & 243 & 3.12 & 22 \\
\hline & {$[12] \mathrm{Co}$} & 16.9 & 0.704 & 243 & 2.90 & 14 \\
\hline
\end{tabular}

loporphyrin-imidazole complex $[(\mathbf{1})(\operatorname{Imi})] \mathrm{Co}^{\mathrm{III}} 7^{+}(2.82 \mathrm{mV})$ (Table 2, column E).

Some trends mirror those found in the octahedral complexes, some are even more pronounced, but some cannot be gleaned from the octahedral complexes. For instance, making the complex more electron-rich, as in [(9) (Imi)] $\mathrm{Co}^{\mathrm{III}} 7^{+}$, increases the electron density of the porphyrin donor set. In turn, this makes the cobalt center more electron-rich, reduces the Lewis acidity and thus weakens the bond to the imidazole donor. This is reflected in the reduction of the $\mathrm{E}_{1 / 2}$ ' value by $16 \%$, to $2.36 \mathrm{mV}$. Chlorin complex $[(4)(\mathrm{Imi})] \mathrm{Co}^{\mathrm{III}} 7^{+}$has a similarly reduced $\mathrm{E}_{1 / 2}{ }^{\prime}$ value $(-15 \%)$, to $2.39 \mathrm{mV}$, as is expected based on the elevated HOMO level of a chlorin compared to that of a porphyrin. Replacement of the meso-phenyl groups in this chlorin by the 3,4,5-trimethoxyphenyl groups reduces the $\mathrm{E}_{1 / 2}$ ' value even further (by $46 \%$ ) to the lowest value measured among all porphyrinoid complexes, $1.51 \mathrm{mV}$.

The other chlorin-type complexes, oxazolochlorin [(6) (Imi) $] \mathrm{Co}^{\mathrm{III}} 7^{+}$and morpholinochlorin $[(3)(\mathrm{Imi})] \mathrm{Co}^{\mathrm{III}} 7^{+}$possess near-identical $\mathrm{E}_{1 / 2}$ ' values $(1.87$ and $1.90 \mathrm{mV})$ that are much below those of the chlorin complex $[(4)(\mathrm{Imi})] \mathrm{Co}^{\mathrm{III}} 7^{+}$. Similarly, the $\mathrm{E}_{1 / 2}$ ' values for the octahedral complexes did not differentiate the chlorins in that dramatic fashion, which may point, for instance, at spin state differences of the complexes of chlorin 4 versus chlorins 3 and $\mathbf{6}$ that will inhibit the kinetics of the ligand loss. Such a possibility is, in fact, supported by computations (see below).

Inversely, the two oxidized porphyrins, dioxochlorin [(7) (Imi) $] \mathrm{Co}^{\mathrm{III}} 7^{+}$and indaphyrin $[(\mathbf{5})(\mathrm{Imi})] \mathrm{Co}^{\mathrm{III}} 7^{+}$have, compared to the chlorins, identical and elevated $\mathrm{E}_{1 / 2}$ ' values ( 2.79 and $2.81 \mathrm{mV})$, but they are essentially identical to $\mathrm{E}_{1 / 2}{ }^{\prime}$ value of the parent porphyrin complex $[(\mathbf{1})(\operatorname{Imi})] \mathrm{Co}^{\mathrm{III}} 7^{+}$, and not above it. Despite the presence of the lactone carbonyl group, porpholactone complex $[(2)(\operatorname{Imi})] \mathrm{Co}^{\mathrm{III}} 7^{+}$is, with an $\mathrm{E}_{1 / 2}{ }^{\prime}$ value of $2.41 \mathrm{mV}$, in the range of an electron-rich porphyrin (such as $[(9)(\operatorname{Imi})] \mathrm{Co}^{\mathrm{III}} 7^{+}$), but not as low as a chlorin. This may be an accurate reflection of its dual nature. In the free base form, porpholactones possess porphyrin-like optical spectra whereas in its metal complexes it is more chlorin-like, even though it lacks the chlorin-typical $\mathrm{sp}^{3}$ carbons at the $\beta$-position. The Brønsted basicity of the free base chromophore was also shown to be an order of magnitude lower than that of the corresponding porphyrin [53].

The three thienylporphyrin complexes $[(\mathbf{1 0})(\mathrm{Imi})] \mathrm{Co}^{\mathrm{III}} 7^{+}$ through $[(\mathbf{1 2})(\mathrm{Imi})] \mathrm{Co}^{\mathrm{III}} 7^{+}$are characterized by similar and

Table 2. Relative Imidazole Binding Energies Recorded for the Dissociation of the Imidazole from [(Por)(Imi)]Co ${ }^{\mathrm{III}} 7^{+}$(Equation 4)

\begin{tabular}{|c|c|c|c|c|c|c|}
\hline \multicolumn{2}{|l|}{ Processes } & A & B & C & $\mathrm{D}$ & $\mathrm{E}$ \\
\hline \multicolumn{2}{|c|}{$[($ Por $\left.)(\operatorname{Imi})] \mathrm{Co}^{\mathrm{III}}\right\rceil^{+} \rightarrow[$ Por $\left.] \mathrm{Co}^{\mathrm{III}}\right\rceil^{+}+\operatorname{Imi}($ Equation 4$)$} & $\mathrm{E}_{1 / 2}(\% \mathrm{NCE})$ & $\mathrm{E}_{1 / 2}(\mathrm{~V})$ & DOF $(3 \mathrm{~N}-6)$ & $\mathrm{E}_{1 / 2}{ }^{\prime}(\mathrm{mV})$ & $\begin{array}{l}\% \Delta \text { of } E_{1 / 2}{ }^{\prime}[\mathrm{Por}] \mathrm{Co} \\
\text { relative to } \mathrm{E}_{1 / 2}{ }^{\prime}[\mathbf{1}] \mathrm{Co}\end{array}$ \\
\hline \multirow[t]{2}{*}{ Porphyrins } & {$[1] \mathrm{Co}$} & 18.4 & 0.711 & 252 & 2.82 & - \\
\hline & [9] $\mathrm{Co}$ & 18.5 & 0.935 & 396 & 2.36 & -16 \\
\hline Porpholactone & {$[2] \mathrm{Co}$} & 15.4 & 0.600 & 249 & 2.41 & -15 \\
\hline \multirow[t]{4}{*}{ Chlorins } & [4] Co & 15.9 & 0.632 & 264 & 2.39 & -15 \\
\hline & {$[8] \mathrm{Co}$} & 11.9 & 0.615 & 408 & 1.51 & -46 \\
\hline & [3] Co & 12.9 & 0.532 & 285 & 1.87 & -34 \\
\hline & {$[6] \mathrm{Co}$} & 12.6 & 0.501 & 264 & 1.90 & -33 \\
\hline \multirow[t]{2}{*}{ Oxoporphyrins } & {$[5] \mathrm{Co}$} & 17.5 & 0.692 & 246 & 2.81 & 0 \\
\hline & [7] $\mathrm{Co}$ & 17.7 & 0.702 & 252 & 2.79 & 1 \\
\hline \multirow[t]{3}{*}{ meso-Thienylporphyrins } & {$[10] \mathrm{Co}$} & 19.2 & 0.793 & 252 & 3.15 & 12 \\
\hline & {$[11] \mathrm{Co}$} & 18.9 & 0.745 & 216 & 3.45 & 22 \\
\hline & {$[12] \mathrm{Co}$} & 17.5 & 0.690 & 216 & 3.19 & 13 \\
\hline
\end{tabular}


significantly higher $\mathrm{E}_{1 / 2}$ ' values than measured for a regular ( $12 \%, 22 \%$, and $13 \%$ higher than the benchmark porphyrin) or oxidized (electron-poor) porphyrins. This parallels the findings for the loss of the first imidazole from the octahedral complexes. It is well established that thienyl groups play a much stronger role in the electronic structure of the porphyrin than the phenyl rings [36]. Our gas-phase findings, in fact, correlate well with the solution data. Bhyrappa and Bhavana found that the first imidazole molecule binds $96 \%$ more strongly to [2-thienylporphyrinato] $\mathrm{Zn}$ (II) (the $\mathrm{Zn}$ analog of $[(\mathbf{1 1}) \mathrm{Co}]$ ) and $15 \%$ more strongly than to [tetraphenylporphyrinato] Zn(II) ( $\mathrm{Zn}$ analog of [(1)Co]) [35]. The same trend was reported for many other nitrogen bases and was explained by the greater inductive effect of the sulfur in 2-thienylporphyrins. Thus, the general trends within the gas phase binding data for the single imidazole in square pyramidal porphyrinid $\mathrm{Co}$ (III) complexes are explained in a rather straightforward fashion while mostly fulfilling expectations based on established porphyrin chemistry principles.

The dissociation energy for the loss of one imidazole from the octahedral complex is, for example for regular porphyrins and thienylporphyrins, lower than the loss of the second imidazole. This surprises from a basic coordination chemistry point of view. The loss in ligand field stabilization energy accompanying the loss of one ligand is expected to be much larger than the increase in metal Lewis acidity caused by the loss of a donor atom. Thus, the loss of the first imidazole was expected to be associated with a significantly higher energy than the loss of the second imidazole. On the other hand, the chlorin complexes show the expected trend.

The explanation may lie in the technique used or it may point at fundamental electronic differences between square pyramidal $\mathrm{Co}$ (III) complexes of porphyrins and chlorin (see also below). Although it is tempting to directly compare the experimental relative binding energies of one and two imidazoles, one should exercise caution when using data derived from the energy-variable CID experiments. Even though this technique has been routinely used to compare relative binding strengths of various noncovalent complexes [29-32, 48], the premise for a valid comparison between two systems lies in similar vibrational properties of the two systems. This is often satisfied by chemical similarities [29]. However, the vibrational properties of square pyramidal and octahedral complexes are substantially different from each other such that a direct comparison may lead to overreaching conclusions.

\section{Computational Studies}

Computational studies were carried out to predict the spin states of the various $\left.\left[(\mathrm{Por})(\mathrm{Imi})_{\mathrm{x}}\right] \mathrm{Co}^{\mathrm{III}}\right\rceil^{+}(\mathrm{x}=0-2)$ complexes and to assess the relationship between kinetic data obtained experimentally and computationally-predicted thermodynamic data. Spin ground states were determined through a combination of optimizations using different multiplicities and wave function stability checks under the M06L/BSA2 model chemistry. As seen previously for related octahedral $\mathrm{Co}$ (III) porphyrin complexes with two imidazole axial ligands [33, 34], they were uniformly ground state singlets (the expected multiplicity for an octahedral $d^{6}$ complex containing high field pyridine-like ligands). Those square planar complexes with no imidazoles were uniformly ground state triplets. Those with one coordinated imidazole were ground state triplets save for chlorin complex [(4)(Imi)] $\mathrm{Co}^{\mathrm{III}} 7^{+}$, which was a borderline singlet using the M06L and wB97XD DFT models. The energy of the triplet state for this was only a few $\mathrm{meV}$ higher in energy; it is possible that different model chemistries would have found this to be the ground state.

Figure 6 shows the relative energies of the frontier orbitals of the $\left[(\mathrm{Por})(\mathrm{Imi})_{2}\right] \mathrm{Co}^{\mathrm{III}} 7^{+}$complexes examined. The HOMO-LUMO gaps are generally similar, with an average value of 1.71(7) eV. As DFT approaches typically do not model the energies of unoccupied orbitals well, it is unclear whether this observation is meaningful, but it suggests that the complexes do not vary much. The HOMO of trimethoxy-substituted ${ }^{1}\left[(\mathbf{9})(\mathrm{Imi})_{2}\right] \mathrm{Co}^{\mathrm{III}} 7^{+}$, lies $375 \mathrm{meV}$ above that of the parent ${ }^{1}\left[(\mathbf{1})(\operatorname{Imi})_{2}\right] \mathrm{Co}^{\mathrm{III}} 7^{+}$, a result consistent with the greater electron-donor characteristics of porphyrin 9. In contrast, the HOMO energies for 3thienylporphyrin complex ${ }^{1}\left[(\mathbf{1 2})(\mathrm{Imi})_{2}\right] \mathrm{Co}^{\mathrm{III}} 7^{+}$and chlorin complex ${ }^{1}\left[(4)(\mathrm{Imi})_{2}\right] \mathrm{Co}^{\mathrm{III}} 7^{+}$lie $76-92 \mathrm{meV}$ below that of the parent, indicating that the porphyrins in these complexes are more electron-withdrawing than is porphyrin $\mathbf{1}$. These observations are consistent with the CID experiment. To the degree that the frontier orbital energies correlate with imidazole dissociation energies, one expects a dissociation energy trend of $\left[(\mathbf{9})(\mathrm{Imi})_{2}\right] \mathrm{Co}^{\mathrm{III}} 7^{+}<{ }^{1}\left[(\mathbf{1})(\mathrm{Imi})_{2}\right] \mathrm{Co}^{\mathrm{III}} 7^{+}<{ }^{1}[(\mathbf{4})$ $\left.(\operatorname{Imi})_{2}\right] \mathrm{Co}^{\mathrm{III}} 7^{+}$.

It was of interest to determine whether the electronwithdrawing nature of chlorin $\mathbf{4}$ was related to the prediction that $[(4)(\mathrm{Imi})] \mathrm{Co}^{\mathrm{III}} 7^{+}$should uniquely be a ground state singlet. To probe this, we calculated the structures and energetics of the complexes $\left[(\mathbf{1 3})(\mathrm{Imi})_{\mathrm{x}}\right] \mathrm{Co}^{\mathrm{III}} 7^{+}$, where porphyrin $\mathbf{1 3}$ is derived from porphyrin $\mathbf{9}$ by replacement of the electron-rich methoxy substituents in the 3, 4, and 5 positions of the meso-phenyl rings by electron-withdrawing fluorine atoms. The HOMO of $\left.\left[(\mathbf{1 3})(\mathrm{Imi})_{2}\right] \mathrm{Co}^{\mathrm{III}}\right\rceil^{+}$(Figure 6) was predicted to be lowest in energy of all complexes studied, by a considerable margin. Similarly, [(13)(Imi)] $\mathrm{Co}^{\mathrm{III}} 7^{+}$was predicted to be a ground state singlet, with the triplet state lying some $290 \mathrm{meV}$ higher in energy. It thus appears that the HOMO energy of a $\left[(\right.$ Por $\left.)(\mathrm{Imi})_{2}\right] \mathrm{Co}^{\mathrm{III}} 7^{+}$ complex can be used to predict the electron-donating/ withdrawing nature of the porphyrin ligand, and in turn the ground state spin of the product of removal of one imidazole from this complex, [(Por)(Imi) $] \mathrm{Co}^{\mathrm{III}} 7^{+}$.

Energetics for imidazole dissociation reactions for representative $\left[(\mathrm{Por})(\mathrm{Imi})_{\mathrm{x}}\right] \mathrm{CO}^{\mathrm{III}} 7^{+}(\mathrm{x}=1-2)$ complexes appear in Table 3. The data using different computational model 


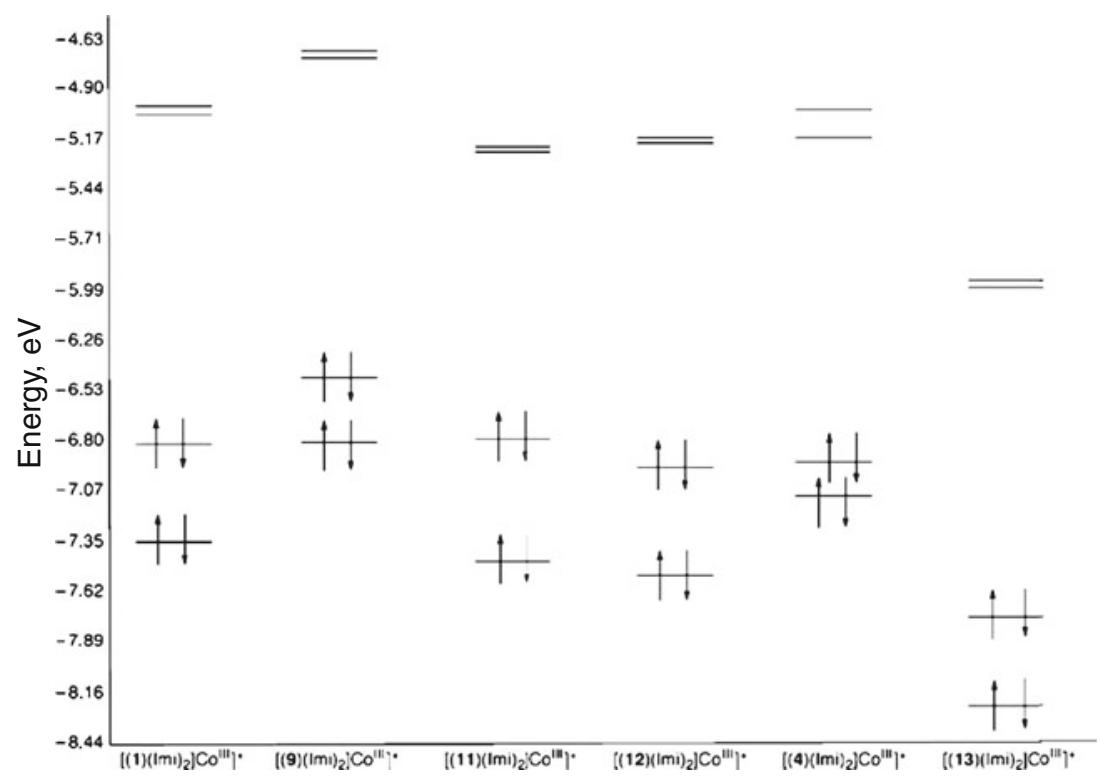

Figure 6. Relative energies (eV) of the HOMO-1, HOMO, LUMO, and LUMO+1 (MO6L/BSA2 level) for [(Por)(Imi) $]_{2} \mathrm{Co}{ }^{\mathrm{III}} 7^{+}$ complexes studied computationally

chemistries generally follow the same trends, although one sees that the DFT models predict sizably larger energies for dissociation of imidazole from $\left[(\right.$ Por $\left.)(\mathrm{Imi})_{2}\right] \mathrm{Co}^{\mathrm{III}} 7^{+}$complexes than does the perturbation theory-based ONIOM $\operatorname{CCSD}(\mathrm{T})$ approach. This holds even for cases like ${ }^{1}[(4)$ $\left.(\mathrm{Imi})_{2}\right] \mathrm{Co}^{\mathrm{III}} 7^{+} \rightarrow{ }^{1}[(4)(\mathrm{Imi})] \mathrm{Co}^{\mathrm{III}} 7^{+}$, where the spin state is maintained. In contrast, all the models including the ONIOM $\operatorname{CCSD}(\mathrm{T})$ approach give quite similar energies for dissociation of imidazole from [(Por)(Imi)]Co $\left.{ }^{\mathrm{III}}\right\rceil^{+}$complexes, save for the case of the chlorin complex ${ }^{1}[(\mathbf{4})(\mathrm{Imi})] \mathrm{Co}^{\mathrm{III}} 7^{+} \rightarrow{ }^{3}[(\mathbf{4})]$ $\mathrm{Co}^{\mathrm{III}} 7^{+}$. This suggests that the ONIOM CCSD(T) approach is more sensitive to changes in spin state than are the DFT models. It is impossible to verify currently whether this sensitivity results in better agreement with experiment, as no experimental energetics are available. As all the model chemistries provide data showing similar trends, we will make comparisons using the M06L/6-31+G(d)//M06L/ BSA2 data.

In contrast with the experiments, for porphyrin complexes $\left[(\right.$ Por $\left.)(\mathrm{Imi})_{\mathrm{n}}\right] \mathrm{Co}^{\mathrm{III}} 7^{+}$(Por=1, 9, 11, and 12;n=1, 2), it is more difficult to remove the first imidazole ligand than to remove the second. Semi-quantitatively, removing the first imidazole requires some $0.5-0.8 \mathrm{eV}$ more energy than removing the second (although the ONIOM $\operatorname{CCSD}(\mathrm{T})$ data

Table 3. Computationally Predicted Energies (eV) for Imidazole Dissociation from $\left[(\right.$ Por $\left.)(\operatorname{Imi})_{2}\right] \mathrm{Co}^{\mathrm{III}} 7^{+}$and $[(\mathrm{Por})(\mathrm{Imi})] \mathrm{Co}^{\mathrm{III}} 7^{+}$

\begin{tabular}{|c|c|c|c|c|c|c|c|}
\hline \multirow[t]{2}{*}{ Processes } & & A & B & $\mathrm{C}$ & $\mathrm{D}$ & E & $\mathrm{F}$ \\
\hline & & M06L/BSA2 & $\begin{array}{l}\% \Delta \text { of } E^{\text {comp }}[\text { por }] \mathrm{Co} \\
\text { relative to } E^{\text {comp }}[1] \mathrm{Co}\end{array}$ & $\% \Delta E^{\text {comp d }}$ & $\begin{array}{l}\mathrm{M} 06 \mathrm{~L}^{\mathrm{a}} \text { 6-31 } \\
+\mathrm{G}(\mathrm{d})\end{array}$ & $\begin{array}{l}\text { wB97XD/ } \\
\text { BSA2 }\end{array}$ & $\begin{array}{l}\mathrm{ONIOM}^{\mathrm{b}} \\
\mathrm{CCSD}(\mathrm{T})\end{array}$ \\
\hline \multirow{6}{*}{ Porphyrins } & $\left.\left.{ }^{1}\left[(\mathbf{1})(\mathrm{Imi})_{2}\right] \mathrm{Co}^{\mathrm{III}}\right\rceil^{+} \rightarrow{ }^{3}[(\mathbf{1})(\mathrm{Imi})] \mathrm{Co}^{\mathrm{IIII}}\right\rceil^{+}$ & 1.88 & - & 43 & 1.79 & 1.94 & 1.33 \\
\hline & $\left.{ }^{3}[(\mathbf{1})(\mathrm{Imi})] \mathrm{Co}^{\mathrm{III}}\right\rceil^{+} \rightarrow{ }^{3}[(\mathbf{1})] \mathrm{Co}^{\mathrm{III}} 7^{+}$ & 1.08 & - & & 1.10 & 1.17 & 1.18 \\
\hline & ${ }^{1}\left[(\mathbf{9})(\mathrm{Imi})_{2}\right] \mathrm{Co}^{\mathrm{III}} 7^{+} \rightarrow{ }^{3}[(\mathbf{9})(\mathrm{Imi})] \mathrm{Co}^{\mathrm{III}} 7^{+}$ & 1.77 & -6 & 45 & 1.77 & n.d. & 1.29 \\
\hline & ${ }^{3}[(9)(\operatorname{Imi})] \mathrm{Co}^{\mathrm{III}} 7^{+} \rightarrow{ }^{3}[(9)] \mathrm{Co}^{\mathrm{III}} 7^{+}$ & 0.98 & -9 & & 1.06 & n.d. & 1.16 \\
\hline & ${ }^{1}\left[(\mathbf{1 3})(\operatorname{Imi})_{2}\right] \mathrm{Co}^{\mathrm{IIII}} 7^{+} \rightarrow{ }^{1}[(\mathbf{1 3})(\operatorname{Imi})] \mathrm{Co}^{\mathrm{III}} 7^{+}$ & 1.73 & -8 & 11 & & & \\
\hline & ${ }^{1}[(\mathbf{1 3})(\mathrm{Imi})] \mathrm{Co}^{\mathrm{III}} 7^{+} \rightarrow{ }^{3}[(\mathbf{1 3})] \mathrm{Co}^{\mathrm{III}} 7^{+}$ & 1.54 & 43 & & & & \\
\hline \multirow[t]{4}{*}{ Thienylporphyrins } & ${ }^{1}\left[(\mathbf{1 1})(\mathrm{Imi})_{2}\right] \mathrm{Co}^{\mathrm{III}} 7^{+} \rightarrow{ }^{3}[(\mathbf{1 1})(\mathrm{Imi})] \mathrm{Co}^{\mathrm{IIII}} 7^{+}$ & 1.83 & -3 & 40 & 1.66 & 1.98 & 1.35 \\
\hline & ${ }^{3}[(\mathbf{1 1})(\mathrm{Imi})] \mathrm{Co}^{\mathrm{III}} 7^{+} \rightarrow{ }^{3}[(\mathbf{1 1})] \mathrm{Co}^{\mathrm{III}} 7^{+}$ & 1.10 & 2 & & 1.14 & 1.20 & 0.90 \\
\hline & $\left.\left.{ }^{1}\left[(\mathbf{1 2})(\mathrm{Imi})_{2}\right] \mathrm{Co}^{\mathrm{III}}\right\rceil^{+} \rightarrow{ }^{3}[(\mathbf{1 2})(\operatorname{Imi})] \mathrm{Co}^{\mathrm{IIII}}\right\rceil^{+}$ & 1.86 & -1 & 43 & n.d. & 1.93 & n.d. \\
\hline & ${ }^{3}[(\mathbf{1 2})(\mathrm{Imi})] \mathrm{Co}^{\mathrm{III}} 7^{+} \rightarrow{ }^{3}[(\mathbf{1 2})] \mathrm{Co}^{\mathrm{III}} 7^{+}$ & 1.07 & -1 & & n.d. & 1.17 & n.d. \\
\hline \multirow[t]{2}{*}{ Chlorin } & ${ }^{1}\left[(4)(\operatorname{Imi})_{2}\right] \mathrm{Co}^{\mathrm{III}} 7^{+} \rightarrow{ }^{1}[(4)(\operatorname{Imi})] \mathrm{Co}^{\mathrm{III}} 7^{+}$ & 1.63 & -13 & 6 & 1.62 & 1.88 & 1.36 \\
\hline & ${ }^{1}[(4)(\operatorname{Imi})] \mathrm{Co}^{\mathrm{III}} 7^{+} \rightarrow{ }^{3}[(4)] \mathrm{Co}^{\mathrm{IIII}} 7^{+}$ & 1.53 & 42 & & 1.41 & 1.29 & 1.09 \\
\hline
\end{tabular}

${ }^{\mathrm{a}} \mathrm{M} 06 \mathrm{~L} / 6-31+\mathrm{G}(\mathrm{d}) / / \mathrm{M} 06 \mathrm{~L} / \mathrm{BSA} 2$ energy.

${ }^{\mathrm{b}} \mathrm{ONIOM}(\mathrm{CCSD}(\mathrm{T}) / 6-311+\mathrm{G}(2 \mathrm{df}, 2 \mathrm{p}): \mathrm{M} 06 \mathrm{~L} / 6-31 \mathrm{G}(\mathrm{d}) / / \mathrm{M} 06 \mathrm{~L} / \mathrm{BSA} 2$ energy.

${ }^{c}\left(E^{\text {comp }}\right.$ for dissociation process for [porphCo] $)-\left(E^{\text {comp }}\right.$ for dissociation process for [1Co] $)$.

$\mathrm{d}\left[\left(\mathrm{E}^{\mathrm{comp}}\right.\right.$ for process - Equation 3$)-\left(\mathrm{E}^{\mathrm{comp}}\right.$ for process - Equation 4$)\left[/\left(\mathrm{E}^{\mathrm{comp}}\right.\right.$ for process - Equation 3$) \times 100$. 
suggest these values are twice too large). It seems likely that most of this energy results from the need for the spin state to change when the first imidazole is removed. This is supported to a degree by the data for the reactions ${ }^{1}[(\mathbf{4})$ $\left.(\mathrm{Imi})_{2}\right] \mathrm{Co}^{\mathrm{III}} 7^{+} \rightarrow{ }^{1}[(\mathbf{4})(\mathrm{Imi})] \mathrm{Co}^{\mathrm{III}} 7^{+}$, and ${ }^{1}\left[(\mathbf{1 3})(\mathrm{Imi})_{2}\right] \mathrm{Co}^{\mathrm{III}} 7^{+}$ $\rightarrow{ }^{1}[(13)(\mathrm{Imi})] \mathrm{Co}^{\mathrm{III}} 7^{+}$, where the spin state remains a singlet throughout imidazole dissociation. The dissociation energies for both complexes are notably lower than those for the analogous complexes of other porphyrins, particularly for ${ }^{1}[(\mathbf{4})$ $\left.(\mathrm{Imi})_{2}\right] \mathrm{Co}^{\mathrm{III}} 7^{+}$. In like fashion, the energies required for the second imidazole dissociation from the chlorin and trifluoroTPP complexes ${ }^{1}[(\mathrm{Por})(\mathrm{Imi})] \mathrm{Co}^{\mathrm{III}} 7^{+} \rightarrow{ }^{3}[($ Por $)] \mathrm{Co}^{\mathrm{III}} 7^{+}$, where the spin state changes, are notably larger than those required for the analogues. It should be noted that the other, non-M06L model chemistries do not show this behavior so clearly.

The computational data appear to support the experimental observation and frontier orbital-based prediction that the methoxy-substituted complexes $\left[(\mathbf{9})(\mathrm{Imi})_{\mathrm{n}}\right] \mathrm{Co}^{\mathrm{III}} 7^{+}$bind imidazole more weakly than do the corresponding parent $[(\mathbf{1})$ $\left.(\mathrm{Imi})_{\mathrm{n}}\right] \mathrm{Co}^{\mathrm{III}} 7^{+}$complexes. However, the impact of the multiple donor substituents appears subtle, as the differences are on the order of $0.03 \mathrm{eV}$. To probe whether [(9)(Imi) ${ }_{\mathrm{n}}$ ] $\mathrm{Co}^{\mathrm{III}} 7^{+}$complexes contain detectably more electron-rich Co centers than do $\left[(\mathbf{1})(\mathrm{Imi})_{\mathrm{n}}\right] \mathrm{Co}^{\mathrm{III}} 7^{+}$complexes, we examined NBO and Hirshberg charges. However, both approaches gave identical values for the charges on Co centers in analogous complexes, so we conclude that the degree of electron richness cannot be distinguished by these methods for these types of complexes.

In keeping with this view, the calculations do not reflect the sizable increase in imidazole binding for the thienylporphyrins $\left[(\mathbf{1 1})(\mathrm{Imi})_{\mathrm{n}}\right] \mathrm{Co}^{\mathrm{III}} 7^{+}$and $\left[(\mathbf{1 2})(\mathrm{Imi})_{\mathrm{n}}\right] \mathrm{Co}^{\mathrm{III}} 7^{+}$seen experimentally. Whereas experiments find these binding imidazole about $15 \%$ more strongly than do the [(1)(Imi $\left.)_{n}\right]$ $\mathrm{Co}^{\mathrm{III}} 7^{+}$complexes, theory suggests essentially identical binding energies. It is possible that this particular distinction arises from the presence of multiple conformations of the thienyl substituents in the gas phase experiments that are not reflected in the computations. It has been shown that such issues affect the photophysics of free [11] and [12] [36].

The M06L-based computational data also appear to support the premise that the energy required to dissociate imidazole from $\left[(4)(\mathrm{Imi})_{2}\right] \mathrm{Co}^{\mathrm{III}} 7^{+}$is smaller than that required to dissociate imidazole from $[(4)(\operatorname{Imi})] \mathrm{Co}^{\mathrm{III}} 7^{+}$, in contrast to the behavior for other complexes because both complexes are ground state singlets, so no spin state change is required to convert from the bis(imidazole) complex to the mono(imidazole) complex. One sees in Table 3 that while the M06L model chemistries predict the reverse, the two energies are much closer than the comparable pairs for other complexes-within $0.2 \mathrm{eV}$. This particular error could reflect errors in the DFT model. It should be noted that the other DFT model chemistry and the ONIOM CCSD(T) approach show larger gaps. However, neither method has been shown to model transition metal complex energetics well, so these results could be erroneous. That similar behavior is observed for the $\left[(\mathbf{1 3})(\mathrm{Imi})_{\mathrm{n}}\right] \mathrm{Co}^{\mathrm{III}} 7^{+}$series supports this view.

\section{Conclusions}

Energy-variable CID was used to determine the relative gasphase binding strength of square pyramidal and octahedral Co(III) complexes of porphyrins, chlorins, and porphyrinanalogues to the first and second axially bound imidazoles. The loss of the imidazole from the octahedral complex largely follows expectations as the ligands dissociate, the more readily the more electron-rich the porphyrin is believed to be. The relative energies required to dissociate the second imidazole from the square pyramidal complex also shows the influence of the macrocycle structure, but in a surprising fashion. While the chlorins show the trends that can be expected based on ligand field stabilization trends, namely that the loss of the last imidazole is per complex more readily accomplished than the loss of the first, the porphyrins and oxoporphyrins show the opposite trend. Here, the loss of the last imidazole is a higher energy process than the loss of the first. This finding points at a change of the electronic structure of the porphyrin cobalt complexes compared with the chlorin cobalt complexes, and may also show the limits of the comparability of CID data for different species. Computations of the thermodynamic ligand stabilities largely back the corresponding parameters derived from kinetic binding experiments.

Thus, this study contributes to the further understanding of porphyrin and chlorin analogues, and further helps to establish the positive ion mode ESI-MS as a premier technique to probe their electronic and structural properties.

\section{Acknowledgments}

This work was supported by the US National Science Foundation (CHE-0517782, CHE-1058846, and CMMI0730826 to $\mathrm{CB}$, and CHE-0130635 to NIU for the purchase of liquid chromatograph-ion trap mass spectrometer used in this work). Support from the Department of Chemistry and Biochemistry of Northern Illinois University is also gratefully acknowledged. The authors thank Junichi Ogikubo and Joshua Akhigbe for experimental assistance in the preparation of select porphyrinoids.

\section{References}

1. Dolphin, D.: The Porphyrins. Academic Press, New York (1978)

2. The Iron and Cobalt Pigments: Biosynthesis, Structure, and Degradation. Volume 12 of The Porphyrin Handbook, Khadish, K. M.; Smith, K. M.; Guilard, R. (eds.) Academic Press, San Diego, (2003)

3. Hsia, C.C.W.: Respiratory function of hemoglobin. New Engl. J. Med. 338, 239-347 (1998)

4. Dennis, M., Kolattukudy, P.E.: A cobalt-porphyrin enzyme converts a fatty aldehyde to a hydrocarbon and CO. Proc. Natl. Acad. Sci. U. S. A. 89, 5306-5310 (1992)

5. Flynn, S.M., George, S.T., White, L., Devonish, W., Takle, G.B.: Water-soluble, meso-substituted cationic porphyrins-a family of compounds for cellular delivery of oligonucleotides. Bio Techniques 26, 736-746 (1999) 
6. Takle, G.B., Thierry, A.R., Flynn, S.M., Peng, B., White, L., Devonish, W., Galbraith, R.A., Goldberg, A.R., George, S.T.: Delivery of oligoribonucleotides to human hepatoma cells using cationic lipid particle conjugated to ferric protoporphyrin IX (Heme). Antisense Nucleic Acid Drug Dev. 7, 177-185 (1997)

7. Blankenship, R.E.: Molecular Mechanisms of Photosynthesis, 2nd edn. Hoboken, Wiley-Blackwell (2008)

8. Milgrom, L.R.: The Colors of Life - an Introduction to the Chemistry of Porphyrins and Related Compounds. Oxford University Press, Oxford (1997)

9. Adler, A.D., Longo, F.R., Finarelli, J.D., Goldmacher, J., Assour, J., Korsakoff, L.: A simplified synthesis for TPP. J. Org. Chem. 32, 476 (1967)

10. Lindsey, J.S.: Synthesis of meso-Substituted Porphyrins. In: Khadish, K.M., Smith, K.M., Guilard, R. (eds.) The Porphyrin Handbook, vol. 1, pp. 45-118. Academic Press, San Diego (2000)

11. Guo, C.-C., Chu, M.-F., Liu, Q., Liu, Y., Guo, D.-C., Liu, X.-Q.: Effective catalysis of simple metalloporphyrins for cyclohexane oxidation with air in the absence of additives and solvents. Appl. Catal. A 246, 303-309 (2003)

12. Ruppel, J.V., Fields, K.B., Snyder, N.L., Zhang, X.P.: Metalloporphyrin-Catalyzed Asymmetric Atom/Group Transfer Reactions. In: Kadish, K.M., Smith, K.M., Guilard, R. (eds.) Handbook of Porphyrin Science, vol. 10, pp. 1-182. World Scientific, Hackensack, New Jersey (2010)

13. Song, E., Shi, C., Anson, F.C.: Comparison of the behavior of several cobalt porphyrins as electrocatalysts for the reduction of $\mathrm{O}_{2}$ at graphite electrodes. Langmuir 14, 4315-4321 (1998)

14. Chen, W., Akhigbe, J., Brückner, C., Li, C.M., Lei, Y.: Electrolytic four-electron reduction of dioxygen by electrochemically deposited Poly $\{[$ meso-Tetrakis(2-Thienyl)Porphyrinato $]$ Cobalt(II) $\}$. J. Phys. Chem. C 114, 8633-8638 (2010)

15. Antonini, E., Brunori, M.: Hemoglobin and Myoglobin in Their Reactions with Ligands, vol. 21, p. 436. North-Holland Publication Co, Amsterdam (1971)

16. Smith, K.M.E.: Porphyrins and Metalloporphyrins. Elsevier, Amsterdam (1975)

17. Scheidt, R.W.: Systematics of the Stereochemistry of Porphyrins and Metalloporphyrins. In: Kadish, K.M., Smith, K.M., Guilard, R. (eds.) The Porphyrin Handbook, vol. 3, pp. 49-112. Academic Press, San Diego (2000)

18. Pasternack, R.F., Gillies, B.S., Stahlbush, J.R.: Kinetics and thermodynamics of the reaction of two iron(III) porphyrins with imidazole and 1methylimidazole in dimethyl sulfoxide. J. Am. Chem. Soc. 100, 26132619 (1978)

19. Walker, F.A., Benson, M.: Thermodynamics of axial ligand competition between 3-picoline and a series of pyridyl ligands covalently attached to zinc tetraphenylporphyrin. J. Am. Chem. Soc. 102, 5530-5538 (1980)

20. Loo, J.A.: Studying noncovalent protein complexes by electrospray ionization mass spectrometry. Mass Spectrom. Rev. 16, 1-24 (1997)

21. Upmacis, R.K., Hajjar, D.P., Chait, B.T., Mirza, U.A.: Direct observation of nitrosylated heme in myoglobin and hemoglobin by electrospray ionization mass spectrometry. J. Am. Chem. Soc. 119 , 10424-10429 (1998)

22. Chen, Y.L., Campbell, J.M., Collins, B.A., Konermann, L., Douglas, D.J.: Stability of a highly charged noncovalent complex in the gas phase: Holomyoglobin. Rapid Commun. Mass Spectrom. 12, 10031010 (1998)

23. Gross, D.S., Zhao, Y.X., Williams, E.R.: Dissociation of heme-globin complexes by blackbody infrared radiative dissociation: molecular specificity in the gas phase? J. Am. Soc. Mass Spectrom. 8, 519-524 (1997)

24. Freitas, M.A., Hendrickson, C.L., Marshall, A.G.: Gas phase activation energy for unimolecular dissociation of biomolecular ions determined by focused radiation for gaseous multiphoton energy transfer (Fragment). Rapid Commun. Mass Spectrom. 13, 1639-1642 (1999)

25. Chen, O., Groh, S., Liechty, A., Ridge, D.P.: Binding of nitric oxide to iron (II) porphyrins: Radiative association, blackbody infrared radiative dissociation, and gas-phase association equilibrium. J. Am. Chem. Soc. 121, 11910-11911 (1999)

26. Cooks, R.G.: Collision-induced dissociation readings and commentary. J. Mass Spectrom. 30, 1215-1221 (1995)

27. Hart, K.J., McLuckey, S.A.: Relative dissociation energy measurements using ion trap collisional activation. J. Am. Soc. Mass Spectrom. 5, 250 259 (1994)
28. Colorado, A., Brodbelt, J.: An empirical approach to estimation of critical energies by using a quadrupole ion trap. J. Am. Soc. Mass Spectrom. 7, 1116-1125 (1996)

29. Jellen, E.E., Chappell, A.M., Ryzhov, V.: Effects of size of noncovalent complexes on their stability during collision-induced dissociation. Rapid Commun. Mass Spectrom. 16, 1799-1804 (2002)

30. Jellen, E.E., Ryzhov, V.: Probing the stability and structure of metalloporphyrin complexes with basic peptides by mass spectrometry. Eur. J. Mass Spectrom. 11, 65-75 (2005)

31. Hayes, L.A., Chappell, A.M., Jellen, E.E., Ryzhov, V.: Binding of metalloporphyrins to model nitrogen bases: Collision-induced dissociation and ion-molecule reaction studies. Int. J. Mass Spectrom. 227, $111-120$ (2003)

32. Vinokur, N., Ryzhov, V.: Using collision-induced dissociation with corrections for the ion number of degrees of freedom for quick comparisons of relative bonding strength. J. Mass Spectrom. 39, 1268-1274 (2004)

33. Liao, M.-S., Scheiner, S.: Electronic structure and bonding in metal porphyrins, metal = Fe, Co, Ni, Cu. Zn. J. Chem. Phys. 117, 205-219 (2002)

34. Liao, M.-S., Watts, J.D., Huang, M.-J.: Effects of peripheral substituents and axial ligands on the electronic structure and properties of cobalt porphyrins. J. Phys. Chem. A 109, 11996-12005 (2005)

35. Bhyrappa, P., Bhavana, P.: meso-Tetrathienylporphyrins: Electrochemical and axial ligation properties. Chem. Phys. Lett. 349, 399-404 (2001)

36. Brückner, C., Foss, P.C.D., Sullivan, J.O., Pelto, R., Zeller, M., Birge, R.R., Crundwell, G.: Origin of the bathochromically shifted optical spectra of meso-Tetrakis-2- and 3-Thienylporphyrins as compared to meso-Tetrakisphenylporphyrin. Phys. Chem. Chem. Phys. 8, 2402-2412 (2006)

37. Brückner, C., Rettig, S.J., Dolphin, D.: Formation of a mesotetraphenylsecochlorin and a homoporphyrin with a twist. J. Org. Chem. 63, 2094-2098 (1998)

38. Fayer, J.: The mysteries of porphyrin chemistry. Chem. Ind., 869-873 (1991)

39. Whitlock Jr., H.W., Hanamer, R., Oester, M.Y., Bower, B.K.: Diimide reduction of porphyrins. J. Am. Chem. Soc. 91, 7485-7489 (1969)

40. Samankumara, L.P., Zeller, M., Krause, J.A., Brückner, C.: Syntheses, structures, modification, and optical properties of meso-Tetraaryl-2,3dimethoxychlorin, and two isomeric meso-Tetraaryl-2,3,12,13-Tetrahydroxybacteriochlorins. Org. Biomol. Chem. 8, 1951-1965 (2010)

41. Daniell, H.W., Williams, S.C., Jenkins, H.A., Brückner, C.: Oxidation of meso-Tetraphenyl-2,3-Dihydroxychlorin: Simplified synthesis of $B$, B'-dioxochlorins. Tetrahedron Lett. 44, 4045-4049 (2003)

42. Gouterman, M., Hall, R.J., Khalil, G.-E., Martin, P.C., Shankland, E.G., Cerny, R.L.: Tetra(Pentafluorophenyl)porpholactone. J. Am. Chem. Soc. 111, 3702 (1989)

43. McCarthy, J.R., Jenkins, H.A., Brückner, C.: Free base meso-TetraarylMorpholinochlorins and porpholactone from meso-Tetraaryl-2,3-Dihydroxychlorin. Org. Lett. 5, 19-22 (2003)

44. McCarthy, J.R., Hyland, M.A., Brückner, C.: Indaphyrin, a mesoTetraphenylsecochlorin-Derived Chromophore Incorporating O-Phenylto-S-Linkages. Chem. Commun. 1738-1739 (2003)

45. McCarthy, J.R., Hyland, M.A., Brückner, C.: Synthesis of indaphyrins: meso-Tetraarylsecochlorin-based porphyrinoids containing direct $\mathrm{O}-$ Phenyl-to-S-Linkages. Org. Biomol. Chem. 2, 1484-1491 (2004)

46. Campbell, C.J., Rusling, J.F., Brückner, C.: Nickel(II) meso-Tetraphenyl-Homoporphyrins, -secochlorins, and -chlorophin: Control of redox chemistry by macrocycle rigidity. J. Am. Chem. Soc. 122, 6679$6685(2000)$

47. McCarthy, J.R., Melfi, P.J., Capetta, S.H., Brückner, C.: Use of Ag(II) as a removable template in porphyrin chemistry: Diol cleavage Products of [meso-Tetraphenyl-2,3-cis-Diolchlorinato]Silver(II). Tetrahedron 59, 9137-9146 (2003)

48. David, W.M., Brodbelt, J.S.: Threshold dissociation energies of protonated amine/polyether complexes in a quadrupole ion trap. $J$. Am. Soc. Mass Spectrom. 14, 383-392 (2003)

49. Frisch, M.J.T.G.W., Schlegel, H.B., Scuseria, G.E., Robb, M.A., Cheeseman, J.R., Scalmani, G., Barone, V., Mennucci, B., Petersson, G.A., Nakatsuji, H., Caricato, M., Li, X., Hratchian, H.P., Izmaylov, A.F., Bloino, J., Zheng, G., Sonnenberg, J.L., Hada, M., Ehara, M., Toyota, K., Fukuda, R., Hasegawa, J., Ishida, M., Nakajima, T., Honda, Y., Kitao, O., Nakai, H., Vreven, T., Montgomery Jr., J.A., Peralta, J.E., Ogliaro, F., Bearpark, M., Heyd, J.J., Brothers, E., Kudin, K.N., Staroverov, V.N., Kobayashi, R., Normand, J., Raghavachari, K., 
Rendell, A., Burant, J.C., Iyengar, S.S., Tomasi, J., Cossi, M., Rega, N., Millam, N.J., Klene, M., Knox, J.E., Cross, J.B., Bakken, V., Adamo, C., Jaramillo, J., Gomperts, R., Stratmann, R.E., Yazyev, O., Austin, A.J., Cammi, R., Pomelli, C., Ochterski, J.W., Martin, R.L., Morokuma, K., Zakrzewski, V.G., Voth, G.A., Salvador, P., Dannenberg, J.J., Dapprich, S., Daniels, A.D., Farkas, Ö., Foresman, J.B., Ortiz, J.V., Cioslowski, J., Fox, D.J.: Gaussian 09, Revision A.02. Gaussian Inc, Wallingford, CT (2009)

50. Zhao, Y., Truhlar, D.G.: The M06 Suite of density functionals for main group thermochemistry, thermochemical kinetics, noncovalent interactions, excited states, and transition elements: Two new functionals and systematic testing of four M06-class functionals and 12 other functionals. Theor. Chem. Acc. 120, 215-241 (2008)

51. Swart, M., Gőell, M., Luis, J. M., Solà, M.: Spin-state-corrected Gaussiantype orbital basis sets. J. Phys. Chem. A. 114, 7191-7197 (2010)

52. Mitin, A.V., Baker, J., Pulay, P.: An improved 6-31g* basis set for firstrow transition metals. J. Chem. Phys. 118, 7775-7782 (2001)

53. Rassolov, V.A., Pople, J.A., Ratner, M.A., Windus, T.L.: 6-31g* basis set for atoms K through Zn. J. Chem. Phys. 109, 1223-1229 (1998)

54. Hehre, W.J., Ditchfield, R., Pople, J.: A self-consistent molecular orbital methods. XII. Further extensions of gaussian-type basis sets for use in molecular orbital studies of organic molecules. J. Chem. Phys. 56, 2257-2261 (1972)

55. Reed, A.E., Curtiss, L.A., Weinhold, F.: Intermolecular interactions from a natural bond orbital, donor-acceptor viewpoint. Chem. Rev. 88, 899-926 (1988)

56. Hirshfeld, F.: Bonded-atom fragments for describing molecular charge densities. Theor. Chem. Acc. 44, 129-138 (1977)

57. Chai, J.D., Head-Gordon, M.: Long-range corrected hybrid density functionals with damped atom-atom dispersion corrections. Phys. Chem. Chem. Phys. 10, 6615-6620 (2008)

58. Vreven, T., Morokuma, K.: On the application of the IMOMO (Integrated Molecular Orbital + Molecular Orbital) method. J. Comput. Chem. 21, 1419-1432 (2000)

59. Dapprich, S., Komáromi, I., Byun, K.S., Morokuma, K., Frisch, M.J.: A new oniom implementation in Gaussian 98. The calculation of energies, gradients and vibrational frequencies and electric field derivatives. $J$. Mol. Struc. (Theochem) 461/462, 1-21 (1999)

60. Khalil, G.E., Daddario, P., Lau, K.S.F., Imtiaz, S., King, M., Gouterman, M., Sidelev, A., Puran, N., Ghandehari, M., Brückner, C.: Oxazolochlorin. 3. meso-Tetraarylporpholactones as high $\mathrm{pH}$ sensors. Analyst 135, 2125$2131(2010)$ 